\title{
Effect of Particle Size Distribution to Remove Contaminants in Groundwater at Dengkil, Selangor.
}

\author{
${ }^{*}$ Nur Aziemah Abd Rashid ${ }^{1, a^{*}}$, Ismail Abustan ${ }^{2, b}$, Mohd Nordin Adlan ${ }^{3, c}$ \\ 1,2,3 School of Civil Engineering, Universiti Sains Malaysia, 14300 Nibong Tebal, Penang. Malaysia. \\ anuraziemahabdrashid@gmail.com, bceismail@usm.my, ccenordin@usm.my
}

Keywords: Groundwater, Riverbank, physical model, alluvium soil, permeability

\begin{abstract}
Particle size distribution (PSD) below ground may influence the groundwater flow rate. Due to that, this study focuses on laboratory scale using local alluvial soil to remove contaminants from river water using different of soil PSD samples. In horizontal permeability modelling shows permeability was influenced by the coefficient of uniformity $(\mathrm{Cu})$ of sand. However, the permeability changes was differ between well and poorly graded sand. Well graded sands $\mathrm{Cu}$ between 4 to 5 the permeability changes are only between $7.8-7.9 \times 10^{-4} \mathrm{~m} / \mathrm{s}$. Whereas poorly graded sands $\mathrm{Cu}$ are between 2.5 to 4 the permeability change between $6.9-9.0 \times 10^{-4} \mathrm{~m} / \mathrm{s}$. Whereas poorly graded sand was shows as consistent media than well graded to remove contaminants and the permeability rate is higher than well graded sand. Poorly graded (Sand B and C) removes turbidity and iron up to $50 \%$. Because of that poorly graded soil is preferable for RBF application.
\end{abstract}

\section{Introduction}

The introduction of groundwater abstraction or riverbank filtration (RBF) is due to the deterioration of water sources from non-point source pollutions. More than that, the impact of using high quantity of chemical in treatment process cannot be ignored as the chemical will affect human health [1]. This system is to improve intake water quality where the water intake process changed from river water to intake process is assisted by well applied several meters from the river pathway [2]. RBF is a new approach in Malaysia which introducing a natural treatment rather than other man-made treatment. Pollutants which is proven can be reduced are colour, turbidity, total coliform, E. coli, Cryptosporidium parvum, dissolve organic matter (DOM), and heavy metal [3]. Weiss et al. [4] had studied on removal of turbidity at the Wabash River Indiana-American Water. Concentrations in the well waters were very constant, within the range generally fell between 0.1 and 1 NTU with some exceptions. Lee et al. [5] had studied on the removal of iron in RBF site at Nakdong River, Korea. The concentration of iron $\left(\mathrm{Fe}^{3+}\right)$ in the riverbank well ranged from 0.00 to $0.09 \mathrm{mg} / \mathrm{l}$, averaging $0.02 \mathrm{mg} / \mathrm{l}$. The concentration of $\mathrm{Fe}^{3+}$ in the river water ranged from 0.00 to $0.18 \mathrm{mg} / \mathrm{l}$, averaging $0.03 \mathrm{mg} / \mathrm{l}$. In general, the iron concentration is low in water. However, the iron concentration of the ambient groundwater of RBF site at Louisville is high in RBF well [6]. The knowledge gap exists concerning the long term performance of the RBF. Soil is the product of biochemical weathering of the parent material $[7,8]$. Weathering process will replace the existing underground soil compaction to be more compressed according to time.

Due to that, this study focuses on the capability of alluvial soil taken from site to remove contaminants from river water. The objective of this study was to reveal the long-term effect on changes of particles size distribution (PSD) for the removal of contaminants (turbidity and iron) in RBF system based on soil collected from the Dengkil site in Selangor. The underground ability to transmit groundwater is a major factor in RBF. Therefore, the characteristic of water flow is taken in this experiment.

\section{Method}

Soil Analysis. The site was located at coordinates $2^{\circ} 53^{\prime} 28.70^{\prime \prime} \mathrm{N}, 101^{\circ} 42^{`} 6.0^{\prime \prime} \mathrm{E}$, Jenderam Hilir, Dengkil, Selangor. At this location, the water and soil samples were taken for the physical model 
test. According to Environmental Quality Report (EQR) 2011, Langat River is a Class III polluted river [9]. Four soil samples were tested by ASTM D 2487-06 standard procedure.

Permeability Measurement. Constant Head Permeability Test (horizontal and vertical) is performed according to Standard procedure ASTM D 2434-68.

Experiment Setup. The setup experiment was simplified in Fig. 1. Physical model was made from Perspex material with dimension $60 \times 20 \times 80 \mathrm{~cm}$. Sand was filled is section B for $7 \mathrm{~cm}$ depth of soil. The flow rate of peristaltic pump was $100 \mathrm{ml} / \mathrm{min}$. The height of water at section A and C (Fig. 1), was measured and recorded as head difference which was used in calculating the permeability of the sand using Darcy Law equation. As the sand in the physical model was saturated with water, the effluent from section $\mathrm{C}$ was gathered in a $120 \mathrm{ml}$ container.

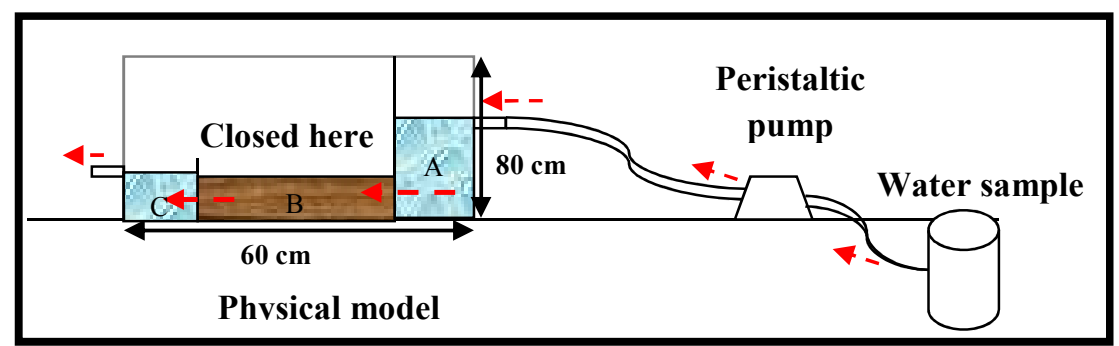

Fig. 1: Physical model experimental setup

Analysis. In order to investigate the effect of sand PSD on the rate of removal of pollutants, all coefficient of uniformity of four sand have different particle size distributions are grouped together in ascending order. In addition to linking PSD of the soil, soil permeability (horizontal permeability) was also studied to understand the changes the soils ability to drain water.

\section{Results and Discussions}

Soil Analysis, Coefficient of Uniformity and Permeability (Horizontal and Vertical) Results. Every sands is obtained different PSD curve. Using sand soil type for all experiment because sand is the most suitable soil type for RBF as applied at Lake Tegel, Germany [10, 11]. Table 1 summarizes the characteristics of sand at Jenderam Hilir, Dengkil, Selangor near the Langat River. From the result of sieve analysis, the range of $\mathrm{D}_{10}, \mathrm{D}_{30}$ and $\mathrm{D}_{60}$ were $0.13 \mathrm{~mm}-0.6 \mathrm{~mm}, 0.3 \mathrm{~mm}-$ $1.0 \mathrm{~mm}$ and $0.59 \mathrm{~mm}-1.5 \mathrm{~mm}$, respectively. The range of calculated $\mathrm{C}_{\mathrm{U}}$ and $\mathrm{C}_{\mathrm{C}}$ were $2.5-4.62$ and $0.95-1.15$, respectively.

Table 1: Result in soil characteristics

\begin{tabular}{cccccccc}
\hline Soil & $\mathbf{C}_{\mathbf{u}}$ & $\mathbf{C}_{\mathbf{c}}$ & $\mathbf{D}_{\mathbf{1 0}(\mathbf{m m})}$ & $\mathbf{D}_{\mathbf{3 0}(\mathbf{m m})}$ & $\mathbf{D}_{\mathbf{6 0}(\mathbf{m m})}$ & Colour & Graded \\
\hline Sand A & 4.62 & 1.15 & 0.13 & 0.30 & 0.60 & White gray & Well \\
Sand B & 3.69 & 0.95 & 0.16 & 0.30 & 0.59 & White gray & Poor \\
Sand C & 2.50 & 1.11 & 0.60 & 1.00 & 1.50 & White gray & Poor \\
Sand D & 4.00 & 1.00 & 0.35 & 0.70 & 1.40 & Black & Well \\
\hline
\end{tabular}




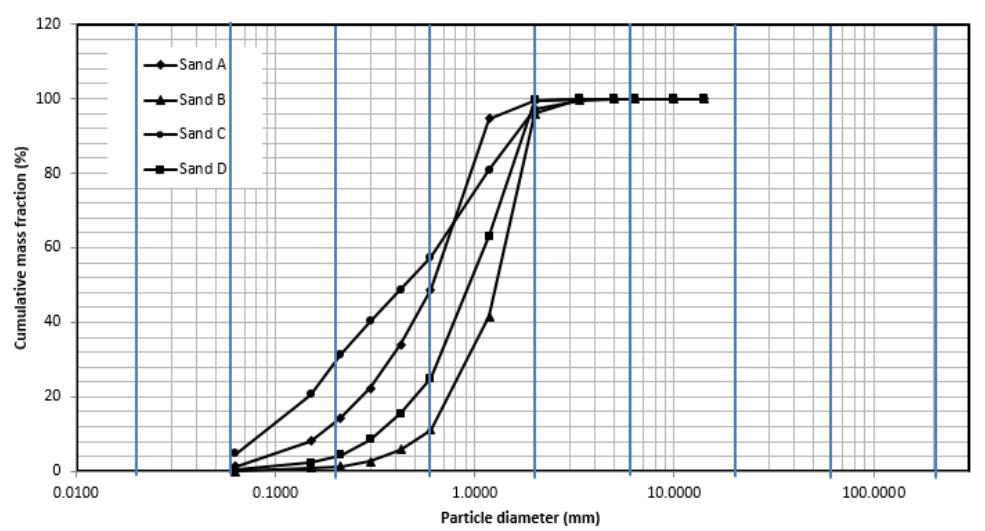

Fig. 2: Graph of particle size distribution for soil sand A, B, C and D.

Coefficient of Uniformity and Permeability (Horizontal and Vertical) Results. In the physical model, the horizontal permeability increased when $\mathrm{Cu}$ is increased for all sand. Fig. 3 shows soil permeability (horizontal and vertical) range is $7.0 \times 10^{-5}$ to $36.0 \times 10^{-4} \mathrm{~m} / \mathrm{s}$. Permeability of well graded sand samples (A and D) are not significantly increase when coefficient of uniformity $(\mathrm{Cu})$ is increased. But permeability of poorly graded sand samples (B and C) are show significant effected when $\mathrm{Cu}$ increased. The effect of sand PSD toward soil permeability needs to be observed because by time, the soil particle in the aquifer may change as the result of the soil physical weathering process [12]. The grain size determines the permeability of sand sample [13].

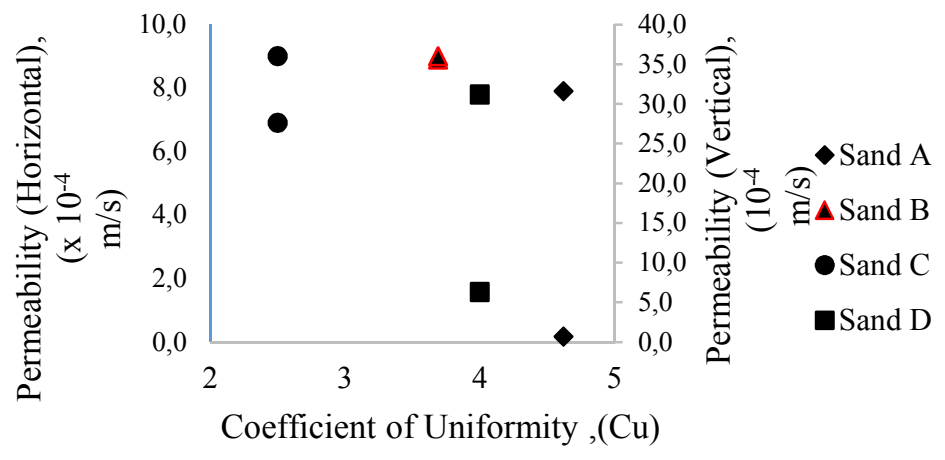

Fig. 3: Relationship between soil permeability and coefficient of uniformity from modeling.

Removal of Pollutants in Modelling of Horizontal Permeability. The removal of turbidity for sand D from $176 \mathrm{NTU}$, to $2.63 \mathrm{NTU}$ is the highest removal than other sand as in Fig. 4. In the previous study by Neudorfer and Weyermays [14], the turbidity was removed from 9.9 NTU to 0.7 NTU which has better result obtained than this study. However, in overall performance of turbidity removal is better than the previous study [14] which marks only $9.9 \mathrm{NTU}$ at initial smaller than the initial turbidity value in this study results with initial $140 \mathrm{NTU}$. Iron is removed from $2.29 \mathrm{mg} / \mathrm{L}$ as Fe to $0.19 \mathrm{mg} / \mathrm{L}$ as $\mathrm{Fe}$ for sand $\mathrm{A}$. The removal percentage is $91.5 \%$. But the range of removal percentage is moved down to $50 \%$ to $80 \%$ for sand $\mathrm{B}$, and $\mathrm{C}$. The capability of soil to remove iron for sand D is very low which is below than $10 \%$ as in Fig. 4. Sand A, B and C showed significant iron removal rather than sand $\mathrm{D}$ which less than $10 \%$. The content of iron was removed by sorption mechanism [15].

Changes in particle size distribution do interfere the removal efficiency of contaminants on ground water. Poorly graded soil (Sand B and C) is consistent to remove iron from ground water above than $50 \%$. Well graded soil (Sand A and D) have a suitable soil particles size distribution for great removal of turbidity contaminant. However, with low permeability, well graded soil (sand D) iron removal is below than $10 \%$ removal. Now in real RBF conditions, pressure will be applied as 
to increase the volume of water yields. Because of that poorly graded sand is suitable for RBF site. With high $\mathrm{C}_{\mathrm{u}}$, soil with poorly graded can raise for better permeability. It is good for the site to have a poorly graded sand and gravel aquifer.

To summarize the capabilities of different sand PSD to remove turbidity and iron, Fig. 5 was constructed. By increasing coefficient of uniformity, the removal of contaminants is increased for all parameters. But removal of turbidity is more prominent and easier to be effected by coefficient of uniformity. The removal iron is not showing a significant relationship towards coefficient of uniformity. This is because all samples are disturbed soil samples whose distribution of particle is not arranged by grain size. The turbidity variation in disturb sample is not influenced by trap coefficient but by travel time which means length of the aquifer. Trap coefficient is the fraction of sediment deposit in the reservoir [16].

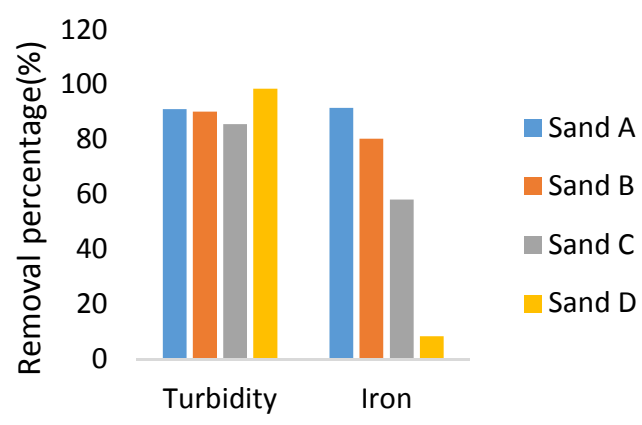

Fig. 4: Removal of turbidity and iron for different sand samples.

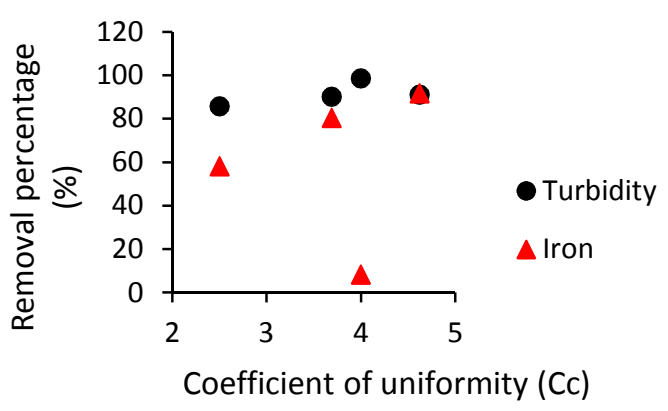

Fig. 5: Percentage removals vs coefficient of uniformity for all sand samples.

\section{Conclusion}

The performance of alluvial soil to remove contaminant depended on particles size distribution, soil graded and soil structure. From the relationship between coefficient of uniformity and removal efficiency, it can be concluded that the highest $\mathrm{Cu}$ has given higher removal efficiency in general. The soil with well graded is not advisable for RBF as it would have low soil permeability. Furthermore, the soil should not have low permeability because pressure will be applied during RBF operations and fine particles may move together with the flowing water. Consequently, it was observed that the performance of the poorly graded alluvial soil has been effective in the reduction of turbidity and iron where the removal consistent up to $50 \%$. Therefore, the poorly graded alluvial soil structure showed the potential result to be as a suitable structure in RBF and should be verified by in-situ test. From the result, it showed that different PSD having different capabilities of removal of different contaminants.

\section{Acknowledgement}

The authors would like to acknowledge the Ministry of Education Malaysia for providing LRGS Grant on Water Security entitled Protection of Drinking Water: Source Abstraction and Treatment (203/PKT/6720006).

\section{References}

[1] NHMRC, Australian Drinking Water Guidelines, 2005.

[2] S. Michael, Systematic comparison of riverbank filtration sites in Austria and India, Doctoral Disertation, Universität Innsbruck, Austria, 2006.

[3] K. M. Hiscock, \& T. Grischeck, Attenuation of groundwater pollution by bank filtration, Journal of hydrology, 266 (4), $139-144$ (2002). 
[4] W. J. Weiss, J. B. Edward, \& A. Ramon, Riverbank filtration for control of microorganisms: Result from field monitoring, Water research, 39(2), 1993 (2005).

[5] J. H. Lee, S. Y. Hamm, J. Y. Cheong, H. S. Kim, E. J. Ko, K. S. Lee, \& S. I. Lee, Characterizing riverbank-filtered water and river water qualities at a site in the lower Nakdong River basin, Republic of Korea, Journal of Hydrology, 376(9), 209-220 (2009).

[6] J. Wang, Riverbank filtration case study at Louisville, Kentucky, Journal of Water Science and Technology, 43(3), 117-145 (2002).

[7] A. E. Jenny, Atlas of Sedimentary Rocks Under the Microscope, Amsterdam: Longman, 1941.

[8] J. R. L. Brady, Sedimentary Structures, Elseviers, Amsterdam, 1990.

[9] DOE, Environmental quality report (EQR), 2011.

[10] H. Bruhl, Sommer-von, \& C. Jarmersted, Report: Investigation land cable route at Lake Tegel (waterworks Tegel - Tegelort transformer stations). Institute of Applied Geology at the Free University of Berlin, unpublished work (1986).

[11] Pachur, J. Hans, \& W. Haberland, Morphological studies on the development of Lake Tegel (Berlin), Journal of Soil, 108(4), 320-341 (1977).

[12] D. P. Thomas, \& R. C. Bradley, Handbook of weather, climate, and water: dynamics, climate, physical meteorology, weather systems, and measurements. United States, Wiley-Interscience, 2003.

[13] A. F. Salarashayeri, \& M. Siosemerde, Prediction of soil hydraulic conductivity from particlesize distribution, World Academy of Science, Engineering and Technology, 61(12), 454-458 (2012).

[14] W. Neudofer, \& H. Weyermayr, Securing groundwater use and reestablishing the water balance by artificial recharge of groundwater in the region of Marchfeld, Austria, Freshwater Biology, 52, 252-266. doi:10.1111/j.1365-2427.2006.01680.x (2007).

[15] C. K. Schmidt, T. L. Frank, B. Heinz-Jurgen, \& K. Wolfgang, Experiences with riverbank filtration and infiltration in Germany, Journal of Water Technology, 32(2), 362-378 (2003).

[16] A. K. Thakur, \& C. S. P. Ojha, Variation of turbidity during subsurface abstraction of river water: A case study. International Journal of Sediments Research, 25(10), 355-365 (2009). 